\title{
Impact of Mitral Valve Repair Case Volume on Postoperative Mortality - A Nationwide Korean Cohort Study -
}

\author{
Karam Nam, MD; Eun Jin Jang, PhD; Jun Woo Jo; Jae Woong Choi, MD; \\ Jun Gi Jo, BSc; Jaehun Lee, MD; Ho Geol Ryu, MD, PhD
}

\begin{abstract}
Background: Although mitral valve repair is recommended over replacement due to better outcomes, repair rates vary significantly among centers. This study examined the effect of institutional mitral valve repair volume on postoperative mortality.

Methods and Results: All cases of adult mitral valve repair performed in Korea between 2009 and 2016 were analyzed. The association between case volume and 1-year mortality was analyzed after categorizing centers according to the number of mitral valve repairs performed as low-, medium-, or high-volume centers $(<20,20-40$, and $>40$ cases/year, respectively). The effect of case volume on cumulative all-cause mortality was also assessed. In all, 6,041 mitral valve repairs were performed in 86 centers. The 1-year mortality in low-, medium-, and high-volume centers was 10.1\%, 8.7\%, and 4.7\%, respectively. Low- and medium-volume centers had increased risk of 1-year mortality compared with high-volume centers, with odds ratios of 2.80 ( $95 \%$ confidence interval [Cl] 2.15-3.64; $\mathrm{P}<0.001)$ and $2.66(95 \% \mathrm{Cl} 1.94-3.64 ; \mathrm{P}<0.001)$, respectively. The risk of cumulative all-cause mortality was also worse in low- and medium-volume centers, with hazard ratios of $1.96(95 \% \mathrm{Cl} 1.68-2.29 ; \mathrm{P}<0.001)$ and $1.77(95 \% \mathrm{Cl} 1.47-2.12$; $\mathrm{P}<0.001)$, respectively.
\end{abstract}

Conclusions: Lower institutional case volume was associated with higher mortality after mitral valve repair. A minimum volume standard may be required for hospitals performing mitral valve repair to guarantee adequate outcome.

Key Words: Case volume; Mitral valve repair; Outcomes

M itral valve (MV) surgery is the treatment of choice for patients with symptomatic primary mitral regurgitation, $, 1,2$ and the surgical volume is rapidly increasing. ${ }^{3}$ Due to advances in evaluation tools and technology, mitral regurgitation patients who are asymptomatic but have poor predicted prognosis are identified early and recommended to undergo surgical intervention. $^{4-7}$ Lower operative mortality, left ventricular function preservation, and freedom from prosthesis-related complications are proposed advantages of MV repair over MV replacement. ${ }^{8}$ Surgeons and hospitals with a higher volume of MV procedures have a greater proportion of MV repairs than MV replacements, which may, in turn, explain better outcomes associated with higher case volume. ${ }^{9}$ Accordingly, guidelines from major professional societies uniformly suggest that MV repair should be pre- ferred to MV replacement when the results are expected to be successful and durable.,2,45

However, the proportion of MV repair to MV replacement varies considerably across surgeons and hospitals, ${ }^{10}$ implying that patients who undergo MV replacement in one hospital may receive MV repair in another. Proposed explanations seem to stem from the complexity of the MV repair procedure, which requires not only skilled cardiac surgeons, but also experienced cardiologists and/or cardiac anesthesiologists with expertise in identifying suitable patients for repair, as well as accurate perioperative assessment, including prognostication of residual regurgitation immediately after repair. ${ }^{11}$

In this regard, the cumulative MV repair experience of cardiac surgery centers may contribute significantly to patient outcome after MV repair. Furthermore, a previous

Received December 16, 2019; revised manuscript received May 11, 2020; accepted June 8, 2020; J-STAGE Advance Publication released online August 1, 2020 Time for primary review: 57 days

Department of Anesthesiology and Pain Medicine, Seoul National University Hospital, Seoul National University College of Medicine, Seoul (K.N., J.L., H.G.R.); Department of Information Statistics, Andong National University, Gyeongsangbuk-do (E.J.J.); Department of Statistics, Kyungpook National University, Daegu (J.W.J., J.G.J.); and Department of Thoracic and Cardiovascular Surgery, Seoul National University Hospital, Seoul National University College of Medicine, Seoul (J.W.C.), Korea

Mailing address: Ho Geol Ryu, MD, PhD, Associate Professor, Department of Anesthesiology and Pain Medicine, Seoul National University Hospital, Seoul National University College of Medicine, 101 Daehak-ro, Jongno-gu, Seoul, 03080, Republic of Korea. E-mail: hogeol@gmail.com

All rights are reserved to the Japanese Circulation Society. For permissions, please e-mail: cj@j-circ.or.jp

ISSN-1346-9843 


\begin{tabular}{|c|c|c|c|c|}
\hline & $\begin{array}{c}\text { Low-volume } \\
\text { centers } \\
\text { (<20 cases/year) }\end{array}$ & $\begin{array}{l}\text { Medium-volume } \\
\text { centers } \\
(20-40 \text { cases/year) }\end{array}$ & $\begin{array}{c}\text { High-volume } \\
\text { centers } \\
\text { (>40 cases/year) }\end{array}$ & P-value \\
\hline No. patients & 1,728 & 1,067 & 3,246 & \\
\hline Age (years) & $57 \pm 14$ & $60 \pm 14$ & $59 \pm 13$ & $<0.001$ \\
\hline Female sex & $729(42)$ & $473(44)$ & $1,506(46)$ & 0.017 \\
\hline Hypertension & $1,069(62)$ & $639(60)$ & $2,104(65)$ & 0.007 \\
\hline Diabetes & $215(12)$ & $133(12)$ & $319(10)$ & 0.005 \\
\hline Hyperlipidemia & $316(18)$ & 206 (19) & $596(18)$ & 0.758 \\
\hline Extracardiac arteriopathy & $195(11)$ & $128(12)$ & $285(9)$ & 0.001 \\
\hline Renal impairment & $20(1)$ & $20(2)$ & $43(1)$ & 0.269 \\
\hline Chronic lung disease & $726(42)$ & $489(46)$ & $1,288(40)$ & 0.002 \\
\hline Pulmonary hypertension & $14(1)$ & $11(1)$ & $77(2)$ & $<0.001$ \\
\hline Angina pectoris & $516(30)$ & $285(27)$ & $937(29)$ & 0.199 \\
\hline Recent MIA & $43(2)$ & $24(2)$ & $76(2)$ & 0.912 \\
\hline History of $\mathrm{PCl}$ & $33(2)$ & $19(2)$ & $46(1)$ & 0.383 \\
\hline Congestive heart failure & 548 (32) & $346(32)$ & $1,008(31)$ & 0.684 \\
\hline Atrial fibrillation & $449(26)$ & $317(30)$ & 1,049 (32) & $<0.001$ \\
\hline Atrioventricular block & $11(1)$ & $6(1)$ & $15(1)$ & 0.713 \\
\hline History of sustained VF/VT & $13(1)$ & $10(1)$ & $21(1)$ & 0.620 \\
\hline Rheumatic MV pathology & $224(13)$ & $135(13)$ & $612(19)$ & $<0.001$ \\
\hline Infective endocarditis & $138(8)$ & $75(7)$ & $215(7)$ & 0.203 \\
\hline Concomitant tricuspid valve repair & $393(23)$ & $256(24)$ & $916(28)$ & $<0.001$ \\
\hline Urgent or emergent surgery & $60(3)$ & $11(1)$ & $41(1)$ & $<0.001$ \\
\hline Perioperative RBC transfusion (units) & & & & $<0.001$ \\
\hline $0-2$ & $871(50)$ & $632(59)$ & $1,665(51)$ & \\
\hline $3-5$ & $687(40)$ & $365(34)$ & $1,252(39)$ & \\
\hline$\geq 6$ & $170(10)$ & $70(7)$ & $329(10)$ & \\
\hline
\end{tabular}

Unless indicated otherwise, data are presented as $\mathrm{n}(\%)$ or mean \pm SD. ${ }^{A}$ Diagnosed within 3 months before surgery. $\mathrm{MI}$, myocardial infarction; MV, mitral valve; PCl, percutaneous coronary intervention; RBC, red blood cell; VF/VT, ventricular fibrillation or ventricular tachycardia.

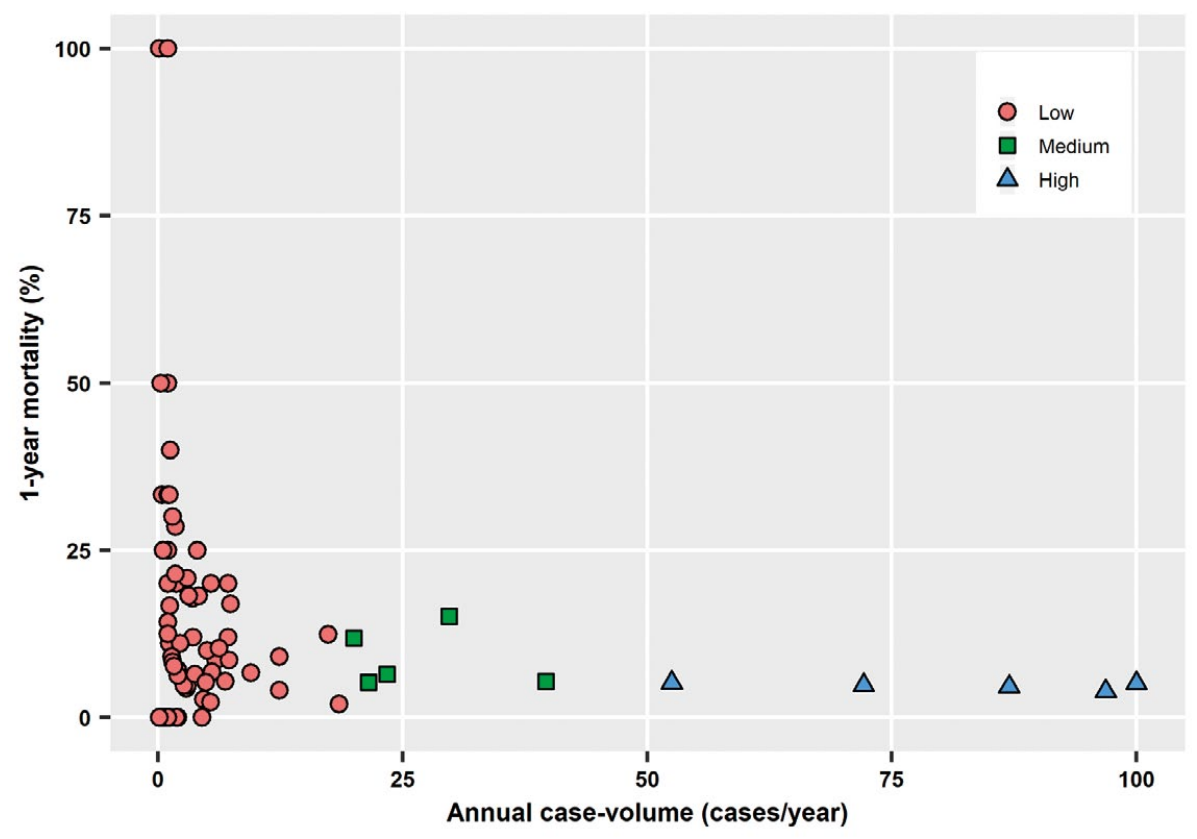

Figure 1. Scatterplot showing the association between case volume and 1-year mortality after mitral valve repair in low-, medium-, and high-volume centers ( $<20,20-40$, and $>40$ cases/year, respectively). 


\begin{tabular}{|c|c|c|c|c|}
\hline & \multicolumn{2}{|l|}{ Unadjusted } & \multicolumn{2}{|l|}{ Adjusted } \\
\hline & OR $(95 \% \mathrm{Cl})$ & P-value & OR $(95 \% \mathrm{Cl})$ & P-value \\
\hline \multicolumn{5}{|l|}{ Case volume strata } \\
\hline High ( $>40$ cases/year) & \multicolumn{2}{|l|}{ Reference } & \multicolumn{2}{|l|}{ Reference } \\
\hline Medium (20-40 cases/year) & $1.93(1.48-2.52)$ & $<0.001$ & $2.66(1.94-3.64)$ & $<0.001$ \\
\hline Low ( $<20$ cases/year) & $2.28(1.82-2.85)$ & $<0.001$ & $2.80(2.15-3.64)$ & $<0.001$ \\
\hline \multicolumn{5}{|l|}{ Age (years) } \\
\hline $18-49$ & \multicolumn{2}{|l|}{ Reference } & \multicolumn{2}{|l|}{ Reference } \\
\hline $50-59$ & $2.69(1.73-4.18)$ & $<0.001$ & $2.02(1.25-3.25)$ & 0.004 \\
\hline $60-69$ & $3.91(2.58-5.93)$ & $<0.001$ & $2.41(1.53-3.82)$ & $<0.001$ \\
\hline $70-79$ & $9.41(6.31-14.03)$ & $<0.001$ & $4.80(3.05-7.56)$ & $<0.001$ \\
\hline$\geq 80$ & $14.26(8.42-24.14)$ & $<0.001$ & $8.85(4.86-16.14)$ & $<0.001$ \\
\hline Female sex & $1.22(1.00-1.49)$ & 0.050 & $0.87(0.69-1.10)$ & 0.253 \\
\hline Hypertension & $1.90(1.51-2.4)$ & $<0.001$ & $1.03(0.78-1.38)$ & 0.818 \\
\hline Diabetes & $2.20(1.79-2.96)$ & $<0.001$ & $1.20(0.89-1.63)$ & 0.232 \\
\hline Hyperlipidemia & $1.92(1.54-2.39)$ & $<0.001$ & $1.06(0.80-1.39)$ & 0.686 \\
\hline Extracardiac arteriopathy & $2.30(1.78-2.98)$ & $<0.001$ & $1.49(1.10-2.02)$ & 0.011 \\
\hline Renal impairment & $7.63(4.80-12.11)$ & $<0.001$ & $2.27(1.26-4.09)$ & 0.007 \\
\hline Chronic lung disease & $1.57(1.29-1.91)$ & $<0.001$ & $1.07(0.85-1.36)$ & 0.554 \\
\hline Pulmonary hypertension & $1.14(0.55-2.36)$ & 0.727 & $1.17(0.49-2.75)$ & 0.725 \\
\hline Angina pectoris & $2.05(1.68-2.51)$ & $<0.001$ & $1.32(1.03-1.69)$ & 0.029 \\
\hline Recent MIA & $2.37(1.47-3.80)$ & $<0.001$ & $1.46(0.82-2.61)$ & 0.195 \\
\hline History of PCl & $3.78(2.31-6.19)$ & $<0.001$ & $0.95(0.51-1.77)$ & 0.862 \\
\hline Congestive heart failure & $1.66(1.35-2.02)$ & $<0.001$ & $1.11(0.86-1.43)$ & 0.432 \\
\hline Atrial fibrillation & $1.52(1.24-1.86)$ & $<0.001$ & $1.19(0.91-1.55)$ & 0.205 \\
\hline Atrioventricular block & $1.38(0.42-4.56)$ & 0.592 & $1.00(0.23-4.35)$ & 0.999 \\
\hline History of sustained VF/VT & $1.34(0.48-3.76)$ & 0.580 & $1.42(0.46-4.35)$ & 0.541 \\
\hline Rheumatic MV pathology & $1.14(0.88-1.48)$ & 0.313 & $1.00(0.74-1.35)$ & 0.999 \\
\hline Infective endocarditis & $1.46(1.04-2.05)$ & 0.029 & $1.47(0.97-2.22)$ & 0.072 \\
\hline Concomitant tricuspid valve repair & $1.45(1.17-1.79)$ & $<0.001$ & $1.08(0.82-1.41)$ & 0.577 \\
\hline Urgent or emergent surgery & $3.00(1.83-4.91)$ & $<0.001$ & $1.36(0.76-2.45)$ & 0.301 \\
\hline \multicolumn{5}{|l|}{ Perioperative RBC transfusion (units) } \\
\hline $0-2$ & \multicolumn{2}{|l|}{ Reference } & \multicolumn{2}{|l|}{ Reference } \\
\hline $3-5$ & $3.56(2.62-4.82)$ & $<0.001$ & $2.88(2.1-3.95)$ & $<0.001$ \\
\hline$\geq 6$ & $30.99(22.81-42.12)$ & $<0.001$ & $24.07(17.2-33.68)$ & $<0.001$ \\
\hline Surgery year & $1.00(0.96-1.04)$ & 0.941 & $0.97(0.92-1.02)$ & 0.286 \\
\hline
\end{tabular}

${ }^{A}$ Diagnosed within 3 months before surgery. $\mathrm{Cl}$, confidence interval; OR, odds ratio. Other abbreviations as in Table 1.

study suggested that mortality after MV repair may not be associated with MV procedure volume.12 It remains unclear whether 'repair only' volume is related to mortality after MV repair. To test this hypothesis, we performed a nationwide cohort study to evaluate the effect of pure MV repair volume of centers on postoperative mortality.

\section{Methods}

The present study was a retrospective, nationwide Korean cohort study. The study protocol was approved by the Institutional Review Board of Seoul National University Hospital (IRB number 1803-058-928). The need for individual patient consent was waived by the review board.

\section{Study Population and Data Collection}

All data were obtained from the National Health Insurance Service (NHIS) database. The NHIS provides healthcare insurance coverage to the vast majority $(>97 \%)$ of residents in Korea. ${ }^{13,14}$ Adult (age $\geq 18$ years) patients who underwent
MV repair between January 2009 and December 2016 in Korea were identified using the billing code for MV repair (O1782). The approach method (median sternotomy or thoracotomy) for MV repair was not specified. Patients who underwent open mitral commissurotomy for mitral stenosis or concomitant cardiac surgical procedures, with the exception of tricuspid valve repair, were excluded from the study. Patient characteristics and preoperative comorbidities were identified using the International Classifications of Diseases, 10th revision (ICD-10) codes. Perioperative transfusion data were also collected using billing codes for transfusion (Table 1). Data regarding in-hospital, 1-year, and cumulative all-cause mortality, as well as reoperation (repair or replacement) on the MV were also obtained.

\section{Definition of Case Volume}

Institutional case volume was defined as the mean number of MV repairs performed per year during the study period. Centers were categorized into 3 groups according to the case volume: high volume ( $>40$ cases/year), medium volume 


\begin{tabular}{|c|c|c|c|c|}
\hline & \multicolumn{2}{|l|}{ Unadjusted } & \multicolumn{2}{|l|}{ Adjusted } \\
\hline & OR $(95 \% \mathrm{Cl})$ & P-value & OR $(95 \% \mathrm{Cl})$ & P-value \\
\hline \multicolumn{5}{|l|}{ Case volume strata } \\
\hline High ( $>40$ cases/year) & \multicolumn{2}{|l|}{ Reference } & \multicolumn{2}{|l|}{ Reference } \\
\hline Medium (20-40 cases/year) & $1.56(1.10-2.22)$ & 0.013 & $2.55(1.69-3.87)$ & $<0.001$ \\
\hline Low ( $<20$ cases/year) & $2.42(1.84-3.19)$ & $<0.001$ & $3.22(2.32-4.48)$ & $<0.001$ \\
\hline \multicolumn{5}{|l|}{ Age (years) } \\
\hline $18-49$ & \multicolumn{2}{|l|}{ Reference } & \multicolumn{2}{|l|}{ Reference } \\
\hline $50-59$ & $3.03(1.72-5.33)$ & $<0.001$ & $2.22(1.20-4.11)$ & 0.011 \\
\hline $60-69$ & $4.32(2.53-7.36)$ & $<0.001$ & $2.69(1.48-4.87)$ & 0.001 \\
\hline $70-79$ & $9.40(5.62-15.74)$ & $<0.001$ & $4.58(2.53-8.26)$ & $<0.001$ \\
\hline$\geq 80$ & $13.01(6.67-25.40)$ & $<0.001$ & $7.91(3.61-17.32)$ & $<0.001$ \\
\hline Female sex & $1.32(1.03-1.69)$ & 0.026 & $0.96(0.72-1.29)$ & 0.797 \\
\hline Hypertension & $1.74(1.32-2.31)$ & $<0.001$ & $1.01(0.71-1.45)$ & 0.937 \\
\hline Diabetes & $2.09(1.53-2.86)$ & $<0.001$ & $0.99(0.68-1.45)$ & 0.970 \\
\hline Hyperlipidemia & $1.93(1.47-2.53)$ & $<0.001$ & $1.04(0.74-1.47)$ & 0.817 \\
\hline Extracardiac arteriopathy & $1.99(1.44-2.77)$ & $<0.001$ & $1.36(0.92-2.02)$ & 0.126 \\
\hline Renal impairment & $5.91(3.41-10.22)$ & $<0.001$ & $1.19(0.61-2.35)$ & 0.608 \\
\hline Chronic lung disease & $1.23(0.96-1.57)$ & 0.104 & $0.83(0.61-1.12)$ & 0.215 \\
\hline Pulmonary hypertension & $1.39(0.59-3.15)$ & 0.463 & $1.68(0.60-4.70)$ & 0.328 \\
\hline Angina pectoris & $2.04(1.59-2.62)$ & $<0.001$ & $1.35(0.98-1.84)$ & 0.063 \\
\hline Recent MIA & $3.28(1.97-5.46)$ & $<0.001$ & $2.18(1.14-4.18)$ & 0.018 \\
\hline History of $\mathrm{PCl}$ & $4.44(2.56-7.70)$ & $<0.001$ & $1.12(0.56-2.26)$ & 0.750 \\
\hline Congestive heart failure & $1.33(1.03-1.71)$ & 0.029 & $0.83(0.60-1.15)$ & 0.273 \\
\hline Atrial fibrillation & $1.45(1.13-1.87)$ & 0.004 & $1.26(0.90-1.77)$ & 0.178 \\
\hline Atrioventricular block & $1.45(0.35-6.11)$ & 0.609 & $1.12(0.19-6.51)$ & 0.898 \\
\hline History of sustained VF/VT & $1.60(0.49-5.19)$ & 0.437 & $2.14(0.57-7.97)$ & 0.258 \\
\hline Rheumatic MV pathology & $1.35(0.99-1.83)$ & 0.055 & $1.19(0.82-1.71)$ & 0.358 \\
\hline Infective endocarditis & $1.65(1.11-2.46)$ & 0.014 & $1.37(0.83-2.24)$ & 0.215 \\
\hline Concomitant tricuspid valve repair & $1.29(0.99-1.68)$ & 0.061 & $0.90(0.64-1.27)$ & 0.548 \\
\hline Urgent or emergent surgery & $4.70(2.82-7.82)$ & $<0.001$ & $1.69(0.90-3.15)$ & 0.101 \\
\hline \multicolumn{5}{|l|}{ Perioperative RBC transfusion (units) } \\
\hline $0-2$ units & Reference & & Reference & \\
\hline $3-5$ units & $9.92(5.26-18.70)$ & $<0.001$ & $8.23(4.34-15.60)$ & $<0.001$ \\
\hline$\geq 6$ units & $130.62(70.42-242.30)$ & $<0.001$ & $107.51(56.82-203.44)$ & $<0.001$ \\
\hline Surgery year & $0.98(0.93-1.04)$ & 0.508 & $0.97(0.91-1.04)$ & 0.433 \\
\hline
\end{tabular}

${ }^{A}$ Diagnosed within 3 months before surgery. Abbreviations as in Tables 1,2.

(20-40 cases/year), and low volume ( $<20$ cases/year).

\section{Study Endpoints and Statistical Analysis}

The primary endpoint was 1-year mortality following MV repair. Secondary endpoints included in-hospital mortality, reoperation of the MV, and cumulative all-cause mortality.

Continuous variables are presented as the mean $\pm \mathrm{SD}$, and categorical variables are given as numbers with percentages. The Chi-squared test was used to compare categorical variables and analysis of variance (ANOVA) was used for comparison between continuous variables.

Univariable and multivariable logistic regression analyses were used to compare 1-year mortality and in-hospital mortality between the case volume strata. All variables listed in Table $\mathbf{1}$ and year of surgery were adjusted for in the multivariable analysis. To compare the risk of reoperation on the MV between the case volume strata, Cox proportional hazards regression was performed. Cumulative survival after MV repair was calculated using the KaplanMeier method and compared using adjusted survival curves and the log-rank test among the case volume strata. Cox proportional hazards regression was then performed to compare the risk of all-cause mortality according to the case volume strata. The same covariates used in the logistic regression were adjusted for in the multivariable Cox regressions. The proportional hazards assumption was tested and verified by plotting log-minus-log curves.

All statistical analyses were performed using SAS 9.4 (SAS Institute, Cary, NC, USA) and R ver. 3.4.3 (R Development Core Team, Vienna, Austria). A P-value of $<0.05$ was considered as statistically significant.

\section{Results}

Baseline Characteristics

In all, 6,041 MV repairs were performed in 86 centers with $1,728,1,067$, and 3,246 patients undergoing MV repair in 76 low-, 5 medium-, and 5 high-volume centers, respectively. The median number of cases per year in the low-, medium-, and high-volume centers was 2 (interquartile range [IQR] 


\begin{tabular}{|c|c|c|c|c|c|}
\hline & \multirow{2}{*}{$\begin{array}{l}\text { No. events } \\
(\%)\end{array}$} & \multicolumn{2}{|c|}{ Unadjusted } & \multicolumn{2}{|c|}{ Adjusted } \\
\hline & & HR $(95 \% \mathrm{Cl})$ & P-value & HR $(95 \% \mathrm{Cl})$ & P-value \\
\hline \multicolumn{6}{|l|}{ Case volume strata } \\
\hline High (>40 cases/year) & $57(1.8)$ & \multicolumn{2}{|c|}{ Reference } & \multicolumn{2}{|c|}{ Reference } \\
\hline Medium (20-40 cases/year) & $27(2.5)$ & $1.53(0.97-2.41)$ & 0.068 & $1.86(1.16-2.98)$ & 0.010 \\
\hline Low (<20 cases/year) & $52(3.0)$ & $1.82(1.25-2.63)$ & 0.002 & $1.91(1.30-2.81)$ & 0.001 \\
\hline \multicolumn{6}{|l|}{ Age (years) } \\
\hline $18-49$ & & \multicolumn{2}{|c|}{ Reference } & \multicolumn{2}{|c|}{ Reference } \\
\hline $50-59$ & & $1.46(0.94-2.26)$ & 0.093 & $1.40(0.89-2.19)$ & 0.145 \\
\hline $60-69$ & & $1.01(0.63-1.60)$ & 0.982 & $0.85(0.51-1.43)$ & 0.536 \\
\hline $70-79$ & & $0.64(0.36-1.13)$ & 0.121 & $0.42(0.23-0.77)$ & 0.005 \\
\hline$\geq 80$ & & $1.21(0.99-3.38)$ & 0.719 & $0.76(0.27-2.13)$ & 0.597 \\
\hline Female sex & & $1.17(0.84-1.64)$ & 0.350 & $1.21(0.87-1.70)$ & 0.251 \\
\hline Hypertension & & $0.68(0.49-0.95)$ & 0.025 & $0.71(0.47-1.06)$ & 0.093 \\
\hline Diabetes & & $0.65(0.34-1.23)$ & 0.182 & $0.65(0.33-1.26)$ & 0.197 \\
\hline Hyperlipidemia & & $1.04(0.68-1.61)$ & 0.853 & $1.21(0.76-1.93)$ & 0.423 \\
\hline Extra-cardiac arteriopathy & & $1.14(0.67-1.95)$ & 0.627 & $1.26(0.71-2.24)$ & 0.424 \\
\hline Renal impairment & & $2.74(1.12-6.70)$ & 0.027 & $1.34(0.53-3.43)$ & 0.538 \\
\hline Chronic lung disease & & $0.91(0.65-1.29)$ & 0.606 & $0.96(0.66-1.39)$ & 0.830 \\
\hline Pulmonary hypertension & & $0.42(0.06-2.95)$ & 0.380 & $0.44(0.06-3.22)$ & 0.417 \\
\hline Angina pectoris & & $0.92(0.63-1.34)$ & 0.649 & $1.02(0.69-1.52)$ & 0.925 \\
\hline Recent MIA & & $0.61(0.15-2.47)$ & 0.492 & $0.66(0.15-2.99)$ & 0.590 \\
\hline History of $\mathrm{PCl}$ & & $0.45(0.06-3.22)$ & 0.426 & $0.35(0.04-2.82)$ & 0.326 \\
\hline Congestive heart failure & & $0.90(0.63-1.31)$ & 0.593 & $0.98(0.65-1.47)$ & 0.913 \\
\hline Atrial fibrillation & & $1.05(0.73-1.51)$ & 0.799 & $1.07(0.70-1.62)$ & 0.762 \\
\hline Atrioventricular block & & $2.97(0.75-11.81)$ & 0.123 & $2.95(0.68-12.79)$ & 0.148 \\
\hline History of sustained VF/VT & & $1.16(0.55-2.43)$ & 0.703 & $1.36(0.65-2.88)$ & 0.416 \\
\hline Rheumatic MV pathology & & $1.37(0.92-2.05)$ & 0.121 & $1.25(0.82-1.90)$ & 0.301 \\
\hline Infective endocarditis & & $2.07(1.26-3.39)$ & 0.004 & $1.48(0.89-2.46)$ & 0.130 \\
\hline Concomitant tricuspid valve repair & & $1.44(1.01-2.06)$ & 0.045 & $1.50(1.01-2.22)$ & 0.046 \\
\hline Urgent or emergent surgery & & $1.15(0.37-3.62)$ & 0.812 & $0.45(0.14-4.45)$ & 0.182 \\
\hline \multicolumn{6}{|l|}{ Perioperative RBC transfusion (units) } \\
\hline $0-2$ & & \multicolumn{2}{|c|}{ Reference } & \multicolumn{2}{|c|}{ Reference } \\
\hline $3-5$ & & $1.68(1.13-2.50)$ & 0.010 & $1.79(1.19-2.70)$ & 0.005 \\
\hline$\geq 6$ & & $4.83(3.12-7.46)$ & $<0.001$ & $5.92(3.76-9.31)$ & $<0.001$ \\
\hline Surgery year & & $1.04(0.97-1.12)$ & 0.300 & $1.04(0.96-1.12)$ & 0.339 \\
\hline
\end{tabular}

${ }^{A}$ Diagnosed within 3 months before surgery. Abbreviations as in Tables 1,2.

1-4), 23 (IQR 22-30), and 87 (IQR 72-97), respectively. Baseline patient characteristics are presented in Table 1.

\section{1-Year Mortality}

The overall 1-year mortality rate after MV repair was 7.0\% $(421 / 6,041)$. The 1-year mortality rates in the low-, medium-, and high-volume centers were $10.1 \%, 8.7 \%$, and $4.7 \%$, respectively. Figure 1 shows 1-year mortality according to annual institutional case volume. Multivariate logistic regression showed that, compared with high-volume centers, 1-year mortality after MV repair was significantly higher in medium- and low-volume centers, with adjusted odds ratios (OR) of 2.66 (95\% confidence interval [CI] 1.94-3.64; $\mathrm{P}<0.001)$ and 2.80 (95\% CI 2.15-3.64; $\mathrm{P}<0.001)$, respectively (Table 2 ).

\section{In-Hospital Mortality}

In-hospital mortality rates after MV repair in low-, medium-, and high-volume centers were $6.9 \%, 4.6 \%$, and $3.0 \%$, respectively, with an overall in-hospital mortality rate of
$4.4 \%(266 / 6,041)$. After adjustment, the risk of in-hospital mortality was significantly higher in low- and mediumvolume than in high-volume centers (ORs 3.22 [95\% CI 2.32-4.48; $\mathrm{P}<0.001]$ and 2.55 [95\% CI 1.69-3.87; $\mathrm{P}<0.001$ ], respectively; Table $\mathbf{3}$ ).

\section{Reoperation on the MV After MV Repair}

After initial MV repair, 136 (2.3\%) patients underwent rerepair $(n=18)$ or replacement $(n=118)$ surgery on the repaired MV: $57(1.8 \%), 27(2.5 \%)$, and $52(3.0 \%)$ patients in the high-, medium-, and low-volume centers, respectively. After adjustment, the risk of MV reoperation was significantly higher in low- and medium-volume centers than in high-volume centers, with adjusted hazard ratios [HRs] of $1.86(95 \%$ CI 1.16-2.98; $\mathrm{P}=0.010)$ and $1.91(95 \%$ CI $1.30-2.81 ; \mathrm{P}=0.001)$, respectively (Table 4).

\section{Cumulative All-Cause Mortality}

The median duration of follow-up for cumulative all-cause mortality was 4.6 years (IQR 2.3-6.8 years). Cumulative 


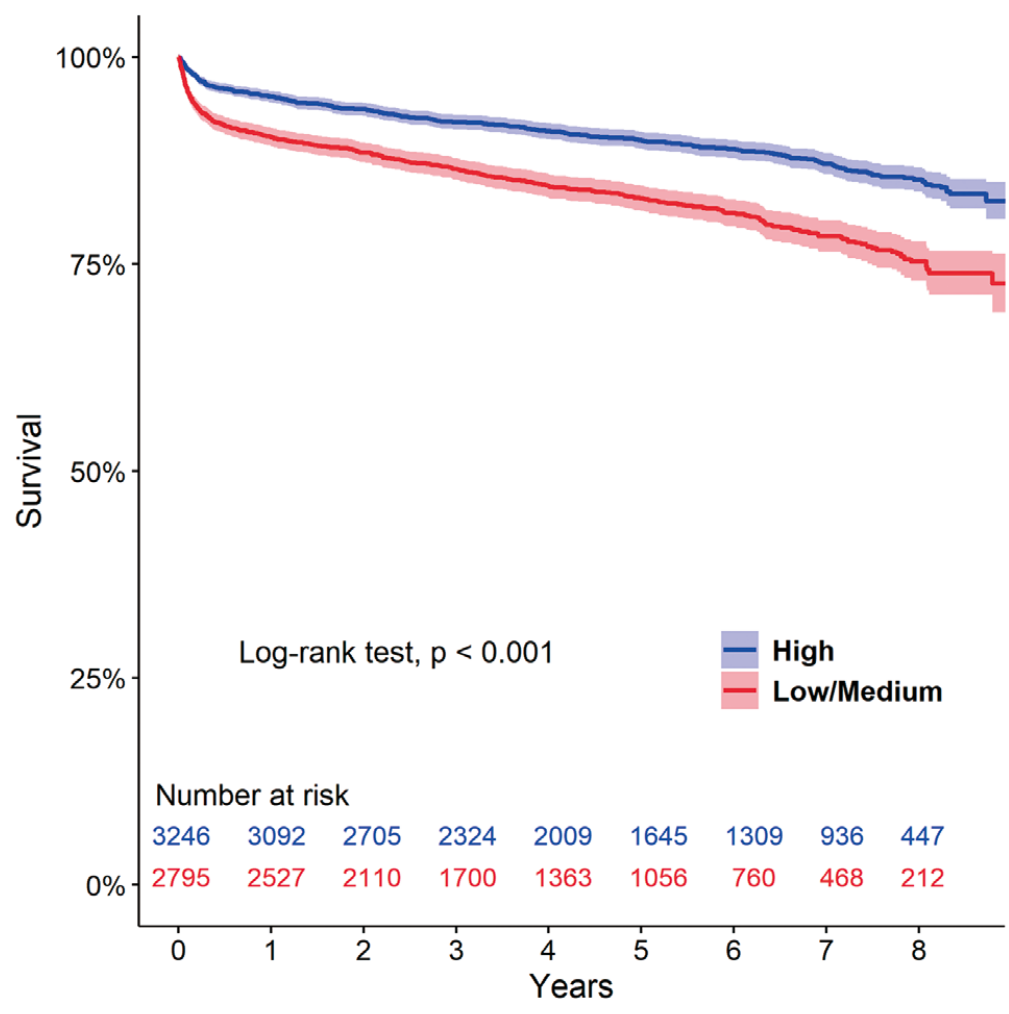

Figure 2. Adjusted survival curves for allcause mortality after mitral valve repair according to institutional case volume. The shaded areas indicate 95\% confidence intervals. High, high-volume centers ( $>40$ cases/year); Low/Medium, combined group of low- and medium-volume centers $(<20$ and 20-40 cases/year, respectively).

1-year survival probability in the low-, medium-, and highvolume centers was 0.89 (95\% CI 0.88-0.91), 0.91 (95\% CI $0.90-0.93)$, and 0.95 (95\% CI 0.94-0.96), respectively, with corresponding cumulative 5-year survival probability of 0.82 (95\% CI $0.80-0.84), 0.83$ (95\% CI $0.80-0.85)$, and 0.90 (0.89-0.91). The adjusted survival curves showed that survival was significantly higher for patients who underwent MV repair in high-volume centers compared with mediumand low-volume centers $(\mathrm{P}<0.001$; Figure 2). Low- and medium-volume centers were combined for the Cox regression analysis because the proportional hazards could not be assumed between the 2 groups. Cox proportional hazards regression showed that the risk of cumulative allcause death for patients in low- or medium-volume centers was significantly higher than for patients in high-volume centers (adjusted HR 1.89; 95\% CI 1.64-2.17; $\mathrm{P}<0.001$; Table 5).

\section{Discussion}

In this nationwide cohort study we found that the risk of 1-year and cumulative all-cause mortality following MV repair was significantly higher in low- $(<20$ cases/year) and medium-volume (20 40 cases/year) centers compared with high-volume ( $>40$ cases/year) centers. The risk of in-hospital mortality and reoperation (re-repair or replacement) on the MV after repair was also higher in medium- and lowvolume centers.

The association between lower case volume and higher mortality has been shown for various complex, high-risk surgical procedures. ${ }^{15,16}$ An inverse relationship between case volume and mortality has been consistently demon- strated for complex, high-risk surgical procedures such as major cancer surgery, ${ }^{\mathbf{1 6 - 1 8}}$ ruptured abdominal aortic aneurysm repair, ${ }^{19}$ carotid endarterectomy, ${ }^{20}$ and solid organ transplantation..$^{\mathbf{2 0}-22}$ Regarding cardiac surgery, the volume-outcome relationship has been largely investigated for coronary artery bypass grafting, for which the results remain somewhat controversial. ${ }^{23-28}$ A few studies also examined the relationship for aortic valve or MV replacement, where higher surgeon or center volume was associated with lower postoperative mortality. ${ }^{29-32}$ However, the volume-outcome relationship in cardiac surgery may arguably remain controversial because it is based on a limited number of studies with modest quality and strength. ${ }^{33}$

Several studies investigated the volume-outcome relationship for MV surgery.9,10,34,35 Although patient populations and study protocols vary slightly, higher surgeon or institutional MV surgery volume was significantly associated with a higher proportion of repair (vs. replacement), which may have contributed to the favorable outcome.,910,35 Moreover, the American College of Cardiology/American Heart Association and the European Society of Cardiology/European Association of Cardio-Thoracic Surgery acknowledged in their guidelines that outcomes following MV repair may depend on the experience of the surgeon or the center., 2,5 Previous studies have used mean annual volume of "all types" of MV surgery to define MV surgery case volume. It is doubtful whether a high case volume of MV replacement would be directly related to favorable outcomes after MV repair in an institution where the case volume for MV repair is low. The counterargument may be that MV repair, such as resection of an isolated $\mathrm{P} 2$ scallop prolapse, is relatively simple and technically straight- 


\begin{tabular}{|c|c|c|c|c|}
\hline & \multicolumn{2}{|c|}{ Unadjusted } & \multicolumn{2}{|c|}{ Adjusted } \\
\hline & HR (95\% Cl) & P-value & HR (95\% Cl) & P-value \\
\hline \multicolumn{5}{|l|}{ Case volume strata } \\
\hline High (>40 cases/year) & \multicolumn{2}{|l|}{ Reference } & \multicolumn{2}{|c|}{ Reference } \\
\hline Low and medium ( $\leq 40$ cases/year) & $1.78(1.56-2.04)$ & $<0.001$ & $1.89(1.64-2.17)$ & $<0.001$ \\
\hline \multicolumn{5}{|l|}{ Age (years) } \\
\hline $18-49$ & \multicolumn{2}{|l|}{ Reference } & \multicolumn{2}{|c|}{ Reference } \\
\hline $50-59$ & $2.40(1.77-3.26)$ & $<0.001$ & $1.94(1.42-2.65)$ & $<0.001$ \\
\hline $60-69$ & $4.74(3.59-6.25)$ & $<0.001$ & $3.21(2.40-4.28)$ & $<0.001$ \\
\hline $70-79$ & 9.68 (7.39-12.68) & $<0.001$ & $5.95(4.46-7.95)$ & $<0.001$ \\
\hline$\geq 80$ & $14.51(10.15-20.75)$ & $<0.001$ & $9.80(6.74-14.25)$ & $<0.001$ \\
\hline Female sex & $1.02(0.89-1.17)$ & 0.774 & $0.74(0.64-0.85)$ & $<0.001$ \\
\hline Hypertension & $1.92(1.64-2.24)$ & $<0.001$ & $1.04(0.88-1.24)$ & 0.634 \\
\hline Diabetes & $2.43(2.06-2.86)$ & $<0.001$ & $1.33(1.12-1.58)$ & 0.001 \\
\hline Hyperlipidemia & $1.90(1.64-2.21)$ & $<0.001$ & $1.06(0.90-1.25)$ & 0.475 \\
\hline Extracardiac arteriopathy & $1.88(1.57-2.26)$ & $<0.001$ & $1.17(0.97-1.42)$ & 0.098 \\
\hline Renal impairment & $7.12(5.41-9.39)$ & $<0.001$ & $2.94(2.17-3.98)$ & $<0.001$ \\
\hline Chronic lung disease & $1.51(1.32-1.72)$ & $<0.001$ & $1.02(0.89-1.17)$ & 0.821 \\
\hline Pulmonary hypertension & $1.11(0.69-1.80)$ & 0.659 & $0.98(0.60-1.61)$ & 0.948 \\
\hline Angina pectoris & $1.76(1.54-2.02)$ & $<0.001$ & $1.12(0.96-1.29)$ & 0.149 \\
\hline Recent MIA & $2.20(1.59-3.03)$ & $<0.001$ & $1.31(0.92-1.85)$ & 0.135 \\
\hline History of $\mathrm{PCl}$ & $3.83(2.79-5.24)$ & $<0.001$ & $1.34(0.95-1.90)$ & 0.099 \\
\hline Congestive heart failure & $1.80(1.57-2.06)$ & $<0.001$ & $1.19(1.02-1.38)$ & 0.026 \\
\hline Atrial fibrillation & $1.55(1.35-1.78)$ & $<0.001$ & $1.14(0.98-1.34)$ & 0.093 \\
\hline Atrioventricular block & $0.95(0.35-2.52)$ & 0.910 & $0.69(0.26-1.86)$ & 0.464 \\
\hline History of sustained VF/VT & $1.16(0.55-2.43)$ & 0.703 & $1.36(0.64-2.87)$ & 0.422 \\
\hline Rheumatic MV pathology & $1.00(0.84-1.19)$ & $>0.999$ & $0.96(0.80-1.15)$ & 0.675 \\
\hline Infective endocarditis & $1.07(0.83-1.39)$ & 0.590 & $1.24(0.95-1.63)$ & 0.112 \\
\hline Concomitant tricuspid valve repair & $1.59(1.38-1.82)$ & $<0.001$ & $1.16(0.99-1.36)$ & 0.061 \\
\hline Urgent or emergency surgery & $2.55(1.84-3.55)$ & $<0.001$ & $1.62(1.14-2.28)$ & 0.007 \\
\hline \multicolumn{5}{|l|}{ Perioperative RBC transfusion (units) } \\
\hline $0-2$ & \multicolumn{2}{|l|}{ Reference } & \multicolumn{2}{|c|}{ Reference } \\
\hline $3-5$ & $2.53(2.13-3.01)$ & $<0.001$ & $2.05(1.72-2.45)$ & $<0.001$ \\
\hline$\geq 6$ & $11.92(9.95-14.29)$ & $<0.001$ & $7.65(6.28-9.30)$ & $<0.001$ \\
\hline Surgery year & $1.03(0.99-1.06)$ & 0.113 & $1.00(0.97-1.04)$ & 0.968 \\
\hline
\end{tabular}

${ }^{A}$ Diagnosed within 3 months before surgery. Abbreviations as in Tables 1,2.

forward, similar to a prosthetic replacement. ${ }^{11}$ However, the proportion of MV repairs (vs. replacement) varies significantly among centers, ${ }^{\mathbf{1 0}}$ and the mean MV repair case volume per cardiac surgeon in the US has been reported to be $<5$ per year. ${ }^{34}$ In addition, even repairing $\mathrm{P} 2$ prolapse may not always be straightforward and can be challenging due to accompanying annular calcification, a shortage of remaining tissue after leaflet resection, potential systolic anterior motion of the MV, or residual regurgitation.11 Considering the uniqueness of MV repair, "repair only" volume should be considered when evaluating the volumeoutcome relationship in MV repair. Of note, a previous study showed that mortality after MV repair was not associated with hospital volume of MV surgery, although the results were not adjusted. ${ }^{12}$ To the best of our knowledge, the present analysis is the first nationwide cohort study that showed a significant inverse relationship between the pure MV repair volume of centers and postoperative mortality.

Surgeon and center volumes of 25 and 50 cases/year, respectively, were proposed as thresholds in a statement on best practices for MV repair in the $\mathrm{UK} .{ }^{36}$ In the present study, patients who underwent MV repair in centers with an annual volume of $\geq 40$ cases had the best outcomes, including postoperative mortality and the risk of reoperation. However, a volume threshold for optimizing MV repair outcome is yet to be established.

The number of MV repairs is increasing rapidly, with $>8,000$ cases performed annually in the US. ${ }^{3}$ Indications for MV repair are expanding with advances in relative fields, such as cardiac surgery, cardiology, and cardiac anesthesia. ${ }^{37,38}$ However, discrepancies between centers in terms of the proportion of MV repairs (vs. replacement), MV repair case volume, and subsequent outcomes persist. ${ }^{10}$ Socioeconomic and ethical issues regarding the distribution of resources and patient outcomes will require careful consideration in the future. Regionalizing the limited resources to a few high-volume centers may improve patient outcome while sacrificing medical accessibility. The optimal balance between outcome and accessibility is unclear and should be contemplated extensively.

There are several limitations to consider in this study. First, this study was retrospective and so the results only 
show an association between institutional case volume and mortality after MV repair. Because all MV repairs performed during the past 8 years in Korea were included in the present study, the results show the whole picture of the current status. Second, many perioperative clinical data, such as the location and severity of the MV lesion, type of MV repair performed, left ventricular function, laboratory findings, medication history, and surgery or cardiopulmonary bypass records could not be obtained because the NHIS database lacked clinical data. In addition, the European System for Cardiac Operative Risk Evaluation (EuroSCORE) II and STS Predicted Risk of Mortality (PROM) score could not be collected, although most of the variables included in both scoring systems were adjusted for in the present study. To minimize the effects of these biases, only concrete outcomes such as mortality and surgical procedure were assessed. Third, the etiology of mitral regurgitation, particularly degenerative and ischemic mitral regurgitation, was not clearly defined using the ICD-10 codes. However, considering the relatively small proportion of patients with rheumatic MV pathology (16.1\%), infective endocarditis $(7.1 \%)$, and recent myocardial infarction $(2.4 \%)$ and/or a history of percutaneous coronary intervention (1.6\%). Most cases are likely to have a degenerative etiology of mitral regurgitation. Fourth, cause of death was not presented due to lack of data. Operative failure may have contributed to the higher chance of death following MV repair in low-volume centers considering the increased risk of inhospital mortality and MV reoperation in these centers. In addition, differences in the capacity of institutions to cope with postoperative complications may have contributed to the different outcomes between institutions with varying case volumes.

In conclusion, institutional case volume of MV repair may be associated with 1-year mortality and cumulative all-cause mortality after MV repair. The lowest postoperative mortality was seen among patients who underwent MV repair in centers performing $\geq 40$ cases of MV repair annually. These results suggest that setting a minimum center volume of MV repair may help achieve optimal patient outcomes after MV repair.

\section{Acknowledgments}

None.

\section{Sources of Funding}

This study did not receive any specific funding.

\section{Disclosures}

The authors declare that they have no conflicts of interest

\section{IRB Information}

This study was approved by the Institutional Review Board of Seoul National University Hospital (1803-058-928).

\section{Data Availability}

The deidentified participant data cannot not be shared because the data used for this study were Korean national administrative data.

\section{References}

1. Tribouilloy CM, Enriquez-Sarano M, Schaff HV, Orszulak TA, Bailey KR, Tajik AJ, et al. Impact of preoperative symptoms on survival after surgical correction of organic mitral regurgitation: Rationale for optimizing surgical indications. Circulation 1999; 99: $400-405$.
2. Adams DH, Rosenhek R, Falk V. Degenerative mitral valve regurgitation: Best practice revolution. Eur Heart J 2010; 31: $1958-1966$.

3. D'Agostino RS, Jacobs JP, Badhwar V, Paone G, Rankin JS, Han JM, et al. The Society of Thoracic Surgeons adult cardiac surgery database: 2017 update on outcomes and quality. Ann Thorac Surg 2017; 103: 18-24

4. Falk V, Baumgartner H, Bax JJ, De Bonis M, Hamm C, Holm PJ, et al. 2017 ESC/EACTS guidelines for the management of valvular heart disease. Eur J Cardiothorac Surg 2017; 52: 616-664.

5. Nishimura RA, Otto CM, Bonow RO, Carabello BA, Erwin JP 3rd, Fleisher LA, et al. 2017 AHA/ACC focused update of the 2014 AHA/ACC guideline for the management of patients with valvular heart disease: A report of the American College of Cardiology/American Heart Association task force on clinical practice guidelines. Circulation 2017; 135: e1159-e1195.

6. Enriquez-Sarano M, Avierinos JF, Messika-Zeitoun D, Detaint D, Capps M, Nkomo V, et al. Quantitative determinants of the outcome of asymptomatic mitral regurgitation. $N$ Engl J Med 2005; 352: 875-883.

7. Sparano DM, Ward RP. Management of asymptomatic, severe mitral regurgitation. Curr Treat Options Cardiovasc Med 2012; 14: $575-583$.

8. Lazam S, Vanoverschelde JL, Tribouilloy C, Grigioni F, Suri RM, Avierinos JF, et al. Twenty-year outcome after mitral repair versus replacement for severe degenerative mitral regurgitation: Analysis of a large, prospective, multicenter, international registry. Circulation 2017; 135: 410-422.

9. LaPar DJ, Ailawadi G, Isbell JM, Crosby IK, Kern JA, Rich JB, et al. Mitral valve repair rates correlate with surgeon and institutional experience. $J$ Thorac Cardiovasc Surg 2014; 148: 995-1003.

10. Chikwe J, Toyoda N, Anyanwu AC, Itagaki S, Egorova NN, Boateng $\mathrm{P}$, et al. Relation of mitral valve surgery volume to repair rate, durability, and survival. J Am Coll Cardiol 2017; 69: 2397-2406.

11. Gillinov M, Mick S, Suri RM. The specialty of mitral valve repair. J Am Coll Cardiol 2017; 69: 2407-2709.

12. Vassileva CM, Boley T, Markwell S, Hazelrigg S. Impact of hospital annual mitral procedural volume on mitral valve repair rates and mortality. J Heart Valve Dis 2012; 21: 41-47.

13. Moon TJ. Light and shadows of the Korean healthcare system. J Korean Med Sci 2012; 27(Suppl): S3-S6.

14. Song SO, Jung CH, Song YD, Park CY, Kwon HS, Cha BS, et al. Background and data configuration process of a nationwide population-based study using the Korean National Health Insurance System. Diabetes Metab J 2014; 38: 395-403.

15. Luft HS, Bunker JP, Enthoven AC. Should operations be regionalized?: The empirical relation between surgical volume and mortality. N Engl J Med 1979; 301: 1364-1369.

16. Begg CB, Cramer LD, Hoskins WJ, Brennan MF. Impact of hospital volume on operative mortality for major cancer surgery. JAMA 1998; 280: 1747-1751.

17. Finlayson EV, Goodney PP, Birkmeyer JD. Hospital volume and operative mortality in cancer surgery: A national study. Arch Surg 2003; 138: $721-725$.

18. Hannan EL, Radzyner M, Rubin D, Dougherty J, Brennan MF. The influence of hospital and surgeon volume on in-hospital mortality for colectomy, gastrectomy, and lung lobectomy in patients with cancer. Surgery $2002 ; 131: 6-15$.

19. Dardik A, Burleyson GP, Bowman H, Gordon TA, Williams $\mathrm{GM}$, Webb TH, et al. Surgical repair of ruptured abdominal aortic aneurysms in the state of Maryland: Factors influencing outcome among 527 recent cases. J Vasc Surg 1998; 28: 413-420.

20. Birkmeyer JD, Stukel TA, Siewers AE, Goodney PP, Wennberg DE, Lucas FL. Surgeon volume and operative mortality in the United States. N Engl J Med 2003; 349: 2117-2127.

21. Edwards EB. Summary of 1994 report of center-specific graft and patient survival rates. In: Terasaki PI, Cecka JM, editors. Clinical transplants 1994. Los Angeles: UCLA Tissue Typing Laboratory, 1994; 541-554.

22. Weiss ES, Meguid RA, Patel ND, Russell SD, Shah AS, Baumgartner WA, et al. Increased mortality at low-volume orthotopic heart transplantation centers: Should current standards change? Ann Thorac Surg 2008; 86: 1250-1259.

23. Shahian DM, Heatley GJ, Westcott GA. Relationship of hospital size, case volume, and cost for coronary artery bypass surgery: Analysis of 12,774 patients operated on in Massachusetts during fiscal years 1995 and 1996. J Thorac Cardiovasc Surg 2001; 122: $53-64$.

24. Sepehripour AH, Athanasiou T. Is there a surgeon or hospital volume-outcome relationship in off-pump coronary artery bypass 
surgery? Interact Cardiovasc Thorac Surg 2013; 16: 202-207.

25. Wen HC, Tang CH, Lin HC, Tsai CS, Chen CS, Li CY. Association between surgeon and hospital volume in coronary artery bypass graft surgery outcomes: A population-based study. Ann Thorac Surg 2006; 81: 835-842.

26. Rathore SS, Epstein AJ, Volpp KG, Krumholz HM. Hospital coronary artery bypass graft surgery volume and patient mortality, 1998-2000. Ann Surg 2004; 239: 110-117.

27. Shroyer AL, Marshall G, Warner BA, Johnson RR, Guo W, Grover FL, et al. No continuous relationship between Veterans Affairs hospital coronary artery bypass grafting surgical volume and operative mortality. Ann Thorac Surg 1996; 61: 17-20.

28. Kim LK, Looser P, Swaminathan RV, Minutello RM, Wong SC, Girardi L, et al. Outcomes in patients undergoing coronary artery bypass graft surgery in the United States based on hospital volume, 2007 to 2011. J Thorac Cardiovasc Surg 2016; 151: 1686-1692.

29. Goodney PP, Stukel TA, Lucas FL, Finlayson EV, Birkmeyer JD. Hospital volume, length of stay, and readmission rates in high-risk surgery. Ann Surg 2003; 238: 161-167.

30. Goodney PP, Lucas FL, Birkmeyer JD. Should volume standards for cardiovascular surgery focus only on high-risk patients? Circulation 2003; 107: 384-387.

31. Patel HJ, Herbert MA, Drake DH, Hanson EC, Theurer PF, Bell $\mathrm{GF}$, et al. Aortic valve replacement: Using a statewide cardiac surgical database identifies a procedural volume hinge point. Ann
Thorac Surg 2013; 96: 1560-1565.

32. Astor BC, Kaczmarek RG, Hefflin B, Daley WR. Mortality after aortic valve replacement: Results from a nationally representative database. Ann Thorac Surg 2000; 70: 1939-1945.

33. Kidher E, Sepehripour A, Punjabi P, Athanasiou T. Do bigger hospitals or busier surgeons do better adult aortic or mitral valve operations? Interact Cardiovasc Thorac Surg 2010; 10: 605-610.

34. Bolling SF, Li S, O'Brien SM, Brennan JM, Prager RL, Gammie JS. Predictors of mitral valve repair: Clinical and surgeon factors. Ann Thorac Surg 2010; 90: 1904-1911.

35. Gammie JS, O'Brien SM, Griffith BP, Ferguson TB, Peterson ED. Influence of hospital procedural volume on care process and mortality for patients undergoing elective surgery for mitral regurgitation. Circulation 2007; 115: 881-887.

36. Bridgewater B, Hooper T, Munsch C, Hunter S, von Oppell U, Livesey S, et al. Mitral repair best practice: Proposed standards. Heart 2006; 92: 939-944.

37. DiBardino DJ, ElBardissi AW, McClure RS, Razo-Vasquez OA, Kelly NE, Cohn LH. Four decades of experience with mitral valve repair: Analysis of differential indications, technical evolution, and long-term outcome. J Thorac Cardiovasc Surg 2010; 139: $76-83$.

38. Cohn LH, Tchantchaleishvili V, Rajab TK. Evolution of the concept and practice of mitral valve repair. Ann Cardiothorac Surg 2015; 4: 315-321. 